\title{
Compact Coating of Tantalum on Tungsten Prepared by Molten Salt Electrodeposition*
}

\author{
Mazhar Mehmood ${ }^{1,2}$, Nobuaki Kawaguchi ${ }^{1}$, Hideki Maekawa ${ }^{1}$, Yuzuru Sato ${ }^{1}$, Tsutomu Yamamura ${ }^{1}$, \\ Masayoshi Kawai ${ }^{3}$, Kenji Kikuchi ${ }^{4}$ and Michihiro Furusaka ${ }^{3}$ \\ ${ }^{1}$ Department of Metallurgy, Graduate School of Engineering, Tohoku University, Sendai 980-8579, Japan \\ ${ }^{2}$ Permanent: Department of Chemical and Materials Engineering, Pakistan Institute of Engineering and Applied Sciences, \\ Islamabad 45650, Pakistan \\ ${ }^{3}$ High Energy Accelerator Research Organization, Tsukuba 305-0801, Japan \\ ${ }^{4}$ Japan Atomic Energy Research Institute, Tokai, Ibaraki 319-1195, Japan
}

Attempts to prepare tantalum coating on tungsten have been performed in $55 \mathrm{~mol} \% \mathrm{LiF}-35 \mathrm{~mol} \% \mathrm{NaF}-10 \mathrm{~mol} \% \mathrm{CaF} 2 \mathrm{melt}$ containing $\mathrm{K}_{2} \mathrm{TaF}_{7}$. Electrolytic deposition of tantalum was carried out by galvanostatic polarization. A conproportionation reaction also occurred that interfered with the electrodeposition and resulted in decrease in current efficiency. However, the product of this reaction was soluble, which diffused away from the electrode without contaminating the deposit. Hence, a compact electrodeposited tantalum coating was obtained on tungsten substrate. An excellent interface was possible when coating was performed in the melt containing $2 \mathrm{~mol}_{\%} \mathrm{~K}_{2} \mathrm{TaF}_{7}$.

(Received April 23, 2003; Accepted May 19, 2003)

Keywords: tantalum, tungsten, coating, molten salt, fluoride, interface, electrodeposition, voltammetry and chronopotentiometry

\section{Introduction}

The sputter-deposited tantalum and other valve-metal alloy coatings, with or without subsequent heat treatment, exhibit extremely high corrosion resistance in aqueous environments. ${ }^{1-7)}$ Tantalum is also interesting for high electric capacitance of its stable oxide film.

Among various techniques used for preparing valve metal coatings, molten salt electrodeposition is extremely useful due to low cost and high flexibility for big size and complicated shape of the objects to be coated. ${ }^{8-10)}$ However, a compact coating making good interface with the substrate has been usually difficult. ${ }^{10)}$ Due to an increased understanding of preparation and properties of molten salts, ${ }^{11-15}$ ) efforts to develop electro-deposited coatings in these electrolytes may succeed to an extent that these could be employed for engineering purposes similarly to the aqueous electrolytes. $^{16)}$

We have been investigating the possibility of electrolytic coating of tantalum on tungsten and nickel in $\mathrm{LiF}-\mathrm{NaF}-\mathrm{CaF}_{2}$ melt containing $\mathrm{K}_{2} \mathrm{TaF}_{7} .{ }^{17)}$ In the present work, we could be able to deposit compact tantalum on tungsten with good interface between the coating and the substrate. The particular attention was also paid to investigate the electrochemical or chemical phenomenon during deposition and dissolution of tantalum.

\section{Experimental Methods}

The details of the experimental procedures are given elsewhere. $^{17)}$ The electrolyte was $55 \% \mathrm{LiF}-35 \% \mathrm{NaF}-$ $10 \% \mathrm{CaF}_{2}$ containing $1-2 \% \mathrm{~K}_{2} \mathrm{TaF}_{7}$ at $700^{\circ} \mathrm{C}$. (The quantities are given in mole percent.) The working electrode, the counter electrode and, the (quasi) reference electrode were a tungsten wire, a graphite rod and, a nickel wire, respectively.

*This Paper was Presented at the Spring Meeting of the Japan Institute of Metals, held in Chiba, on March 29, 2003.
The electrochemical tests included cyclic voltammetry and reverse chronopotentiometry. The electrodeposits were characterized by X-ray analysis and SEM.

\section{Results and Discussion}

\subsection{Electrochemical phenomenon}

Figure 1 shows a typical cyclic voltammogram obtained on tungsten in $\mathrm{LiF}-\mathrm{NaF}-\mathrm{CaF}_{2}$ melt containing $2 \% \mathrm{~K}_{2} \mathrm{TaF}_{7}$. The reactions at two cathodic waves, $\mathrm{R}_{1}$ and $\mathrm{R}_{2}$, are recognized as the reactions (1) and (2), respectively. ${ }^{17)}$

$$
\begin{gathered}
\mathrm{Ta}(\mathrm{V})+3 \mathrm{e}^{-}=\mathrm{Ta}(\mathrm{II}) \\
\mathrm{TaF}_{7}^{2-}+5 \mathrm{e}^{-}=\mathrm{Ta}+7 \mathrm{~F}^{-}
\end{gathered}
$$

The reaction of our interest for electro-deposited coating is the reaction (2). However, the presence of two anodic waves, i.e., $\mathrm{O}_{2}^{\prime}$ and $\mathrm{O}_{2}^{\prime \prime}$, after the cathodic wave $\mathrm{R}_{2}$ for electrodeposition of tantalum, suggested the possibility of an additional (side) reaction during electrodeposition of tantalum. Hence, further investigation was performed by chronopotentiometry.

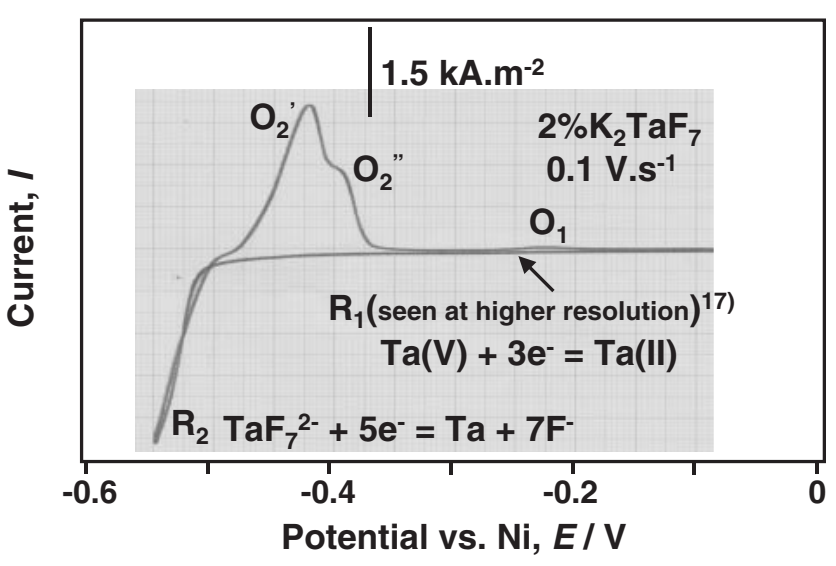

Fig. 1 A typical cyclic voltammogram obtained on tungsten. 
(a) $0.15 \mathrm{kA} \cdot \mathrm{m}^{-2}$
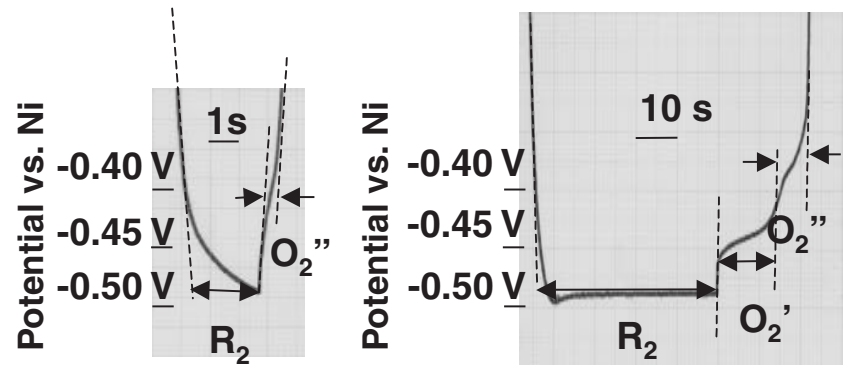

(c) $0.95 \mathrm{kA} \cdot \mathrm{m}^{-2}$

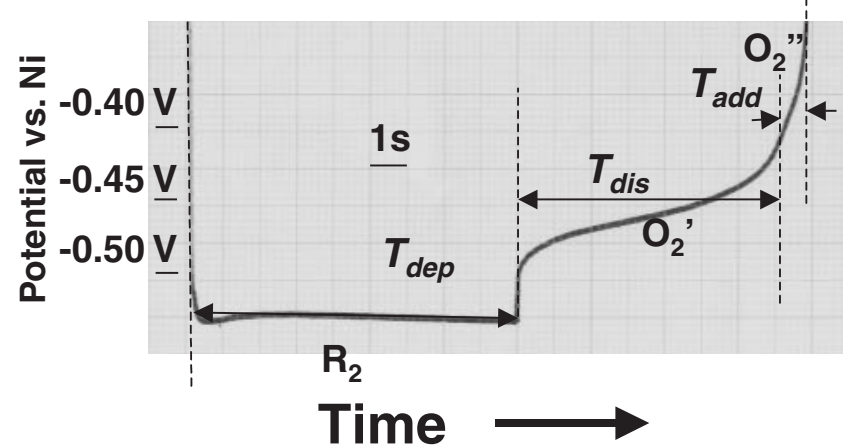

Fig. 2 Typical reverse chronopotentiograms obtained on tungsten in the melt containing $2 \% \mathrm{~K}_{2} \mathrm{TaF}_{7}$.

Figure 2 shows some typical results of reverse chronopotentiometry obtained on tungsten. In Fig. 2(a), only one anodic plateau is recognized, that is possibly, $\mathrm{O}_{2}^{\prime \prime}$. The time spent in this anodic plateau is almost one third of the cathodic plateau $R_{2}$, which is typical for the re-oxidation of a soluble reductant. ${ }^{18)}$ When reduction is continued for a longer time at the same current density, two anodic plateaus, $\mathrm{O}_{2}^{\prime}$ and $\mathrm{O}_{2}^{\prime \prime}$, are observed as shown in Fig. 2(b). The two anodic plateaus are also observed at a very high current density as shown in Fig. 2(c). In these cases, the total time of anodic plateaus is more than $60 \%$ of the time spent in preparing the reductant at $R_{2}$. This suggests that an insoluble reductant is formed at $R_{2}$ and the appearance of the plateau $\mathrm{O}_{2}^{\prime}$ should be related with the oxidation (dissolution) of this insoluble reductant. Since metallic tantalum is formed at $\mathrm{R}_{2},{ }^{17}$ ) the plateau $\mathrm{O}_{2}^{\prime}$ must be related with dissolution of metallic tantalum.

One possibility could be that tantalum is formed at $\mathrm{R}_{2}$ in a single step, while it undergoes oxidation in two steps to give two anodic plateaus, $\mathrm{O}_{2}^{\prime}$ and $\mathrm{O}_{2}^{\prime \prime}$. The other possibility is that another species is formed at $\mathrm{R}_{2}$ besides metallic tantalum which undergoes oxidation at $\mathrm{O}_{2}^{\prime \prime}$. In case of the former possibility, the ratio of the time spent in corresponding plateaus, i.e., $T_{\mathrm{add}} / T_{\mathrm{dis}}$, should be constant as a function of the ratio of the charge transfer numbers. ${ }^{18)}$ If we compare the chronopotentiograms obtained at different current densities and the concentrations of $\mathrm{K}_{2} \mathrm{TaF}_{7}$, the ratio $T_{\text {add }} / T_{\text {dis }}$ is not constant, as partly shown in Fig. 2. Accordingly, the anodic plateaus, $\mathrm{O}_{2}^{\prime}$ and $\mathrm{O}_{2}^{\prime \prime}$, are not related with two-step dissolution of metallic tantalum. Hence, the latter possibility looks closer to the reality that an additional species is formed, besides metallic tantalum, whose oxidation gives rise to the second anodic plateau. Knowing a very common phenomenon of disproportionation (and conproportionation) reaction in molten salts, ${ }^{10)}$ we believe that this species is formed by a conproportionation reaction, i.e., chemical reaction of electro-deposited tantalum with $\mathrm{Ta}(\mathrm{V})$ in order to form an intermediate oxidation state. Because this species oxidizes at active potentials than required for $\mathrm{Ta}(\mathrm{II})$, it appears to be $\mathrm{Ta}(\mathrm{I})$. Based on these considerations, we can suggest the reactions (3) and (4) for the formation and re-oxidation of conproportionation product, respectively.

$$
\begin{gathered}
\mathrm{Ta}(\mathrm{V})+4 \mathrm{Ta}(0)=5 \mathrm{Ta}(\mathrm{I}) \\
\mathrm{Ta}(\mathrm{I})=\mathrm{Ta}(\mathrm{V})+4 \mathrm{e}^{-}
\end{gathered}
$$

We have further analysed the chronopotentiograms obtained at different current densities and time for deposition. Consider Fig. 2(c) and the reactions (2)-(4). The number of moles of tantalum that are deposited at $\mathrm{R}_{2}$ in time $T_{\text {dep }}$ should be $I T_{\mathrm{dep}} / 5 \mathrm{~F}$ according to the Faraday's law. Similarly the number of moles of metallic tantalum that are dissolved at $\mathrm{O}_{2}^{\prime}$ is $I T_{\text {dis }} / 5 \mathrm{~F}$. The difference of these two values $\left(I\left(T_{\text {dep }}-T_{\text {dis }}\right) / 5 \mathrm{~F}\right)$ must be the number of moles of metallic tantalum that undergo the conproportionation reaction (3). In turn the number of moles of $\mathrm{Ta}(\mathrm{I})$ that are formed is $I\left(T_{\text {dep }}-T_{\text {dis }}\right) / 4 \mathrm{~F}$. On the other hand, the number of moles of $\mathrm{Ta}(\mathrm{I})$ that undergo oxidation at $\mathrm{O}_{2}^{\prime \prime}$ by reaction (4) is $I T_{\text {add }} / 4 \mathrm{~F}$. If $q$ is the ratio of the number of moles of $\mathrm{Ta}(\mathrm{I})$ that are oxidized (at $\mathrm{O}_{2}^{\prime \prime}$ by reaction (4)) to that are formed by reaction (3), we can construct the following equation:

$$
T_{\text {add }}=q\left(T_{\text {dep }}-T_{\text {dis }}\right)
$$

If $\mathrm{Ta}(\mathrm{I})$ is completely insoluble and stays in the deposit for electro-oxidation at $\mathrm{O}_{2}^{\prime \prime}$, q should be equal to unity. Figure 3 shows the relationship between $T_{\text {add }}$ and $\left(T_{\text {dep }}-T_{\text {dis }}\right)$. As $q<1, \mathrm{Ta}(\mathrm{I})$ is not insoluble. By contrast, $q$ is approximately equal to $1 / 3$ for most of the cases. It appears that the product of conproportionation reaction, i.e., Ta(I), diffuses into the electrolyte. Only approximately one third returns to the electrode within the anodic plateau $\mathrm{O}_{2}^{\prime \prime}$. The other diffuses into the bulk of the electrolyte. The soluble nature of conproportionation product forming at the tantalum surface indicates that the conproportionation reaction may not cause contamination of the electrodeposits.

Figure 4 shows $T_{\text {dis }} / T_{\text {dep }}$ as a rough measure of current efficiency of the electrodeposition. It is revealed by Fig. 4(a)

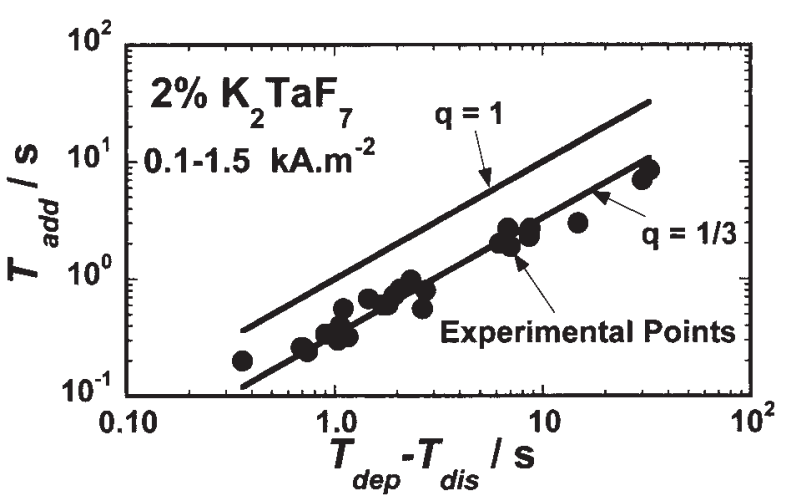

Fig. 3 A relationship of $T_{\text {add }}$ to the $\left(T_{\text {dep }}-T_{\text {dis }}\right)$ obtained at a wide range of current densities and the deposition times. The filled circles are the data points. The solid lines are the plots of eq. (5). 
(a)

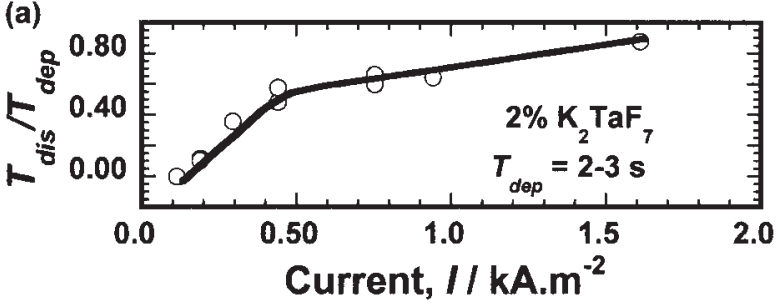

(b)

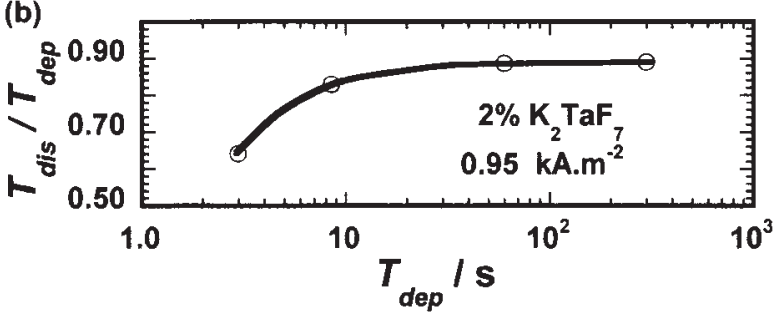

Fig. 4 A typical dependence of apparent current efficiency $\left(T_{\mathrm{dis}} / T_{\mathrm{dep}}\right)$ on the current density (a) and time of deposition (b).

that a high current density for electrodeposition is required for a reasonable current efficiency in order to obtain stable nucleation and growth of the deposit. Furthermore, the severity of conproportionation reaction is higher at the nucleation stage, although it continues to occur with growth of metallic tantalum, as suggested by Fig. 4(b).

\subsection{Morphology of the deposits}

By X-ray analysis, the electrodeposits obtained at 0.15 $1.5 \mathrm{kA} \cdot \mathrm{m}^{-2}$ in the melt containing $2 \% \mathrm{~K}_{2} \mathrm{TaF}_{7}$ were found to be tantalum without contamination of fluoride or other species from the electrolyte. It may be worth mentioning here that the deposits did not cover more than $90 \%$ of the surface when electrodeposition was performed at $0.15-0.2 \mathrm{kA} \cdot \mathrm{m}^{-2}$. However, the surface was completely covered with the electrodeposits obtained at current densities of $0.5-$ $1.5 \mathrm{kA} \cdot \mathrm{m}^{-2}$. This difference may be due to conproportionation reaction, which dissolves tantalum and does not allow stable deposit to nucleate on the tungsten substrate at low current densities in the melt containing $2 \% \mathrm{~K}_{2} \mathrm{TaF}_{7}$. Because dissolution rate is less pronounced in comparison with deposition rate at high current densities, stable deposit easily forms and covers the surface completely.

Figure 5 shows SEM images of the electro-deposited tantalum surface as a function of current density. Two kinds
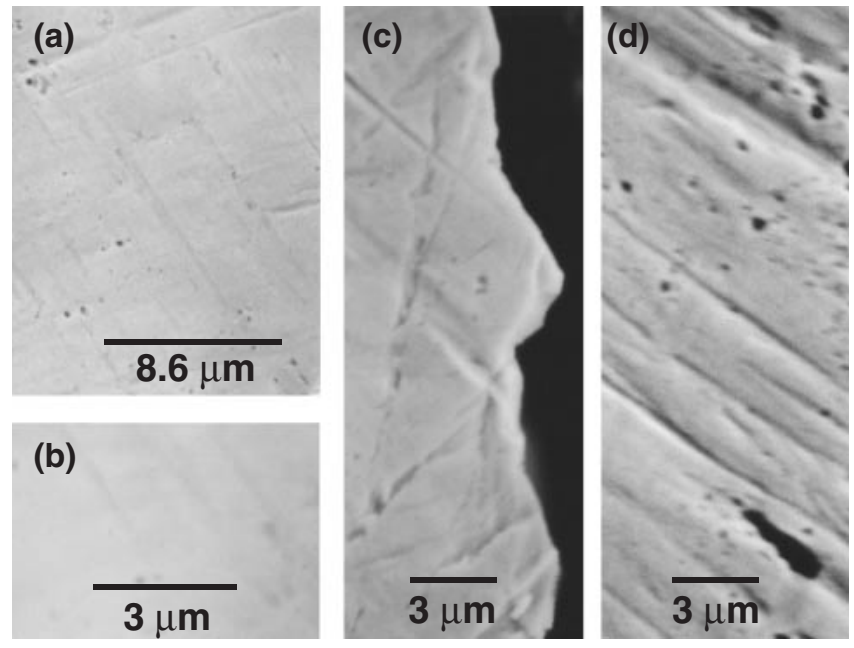

Fig. 6 Sectional view of electro-deposited tantalum obtained at $0.5(\mathrm{a}, \mathrm{b})$, 1.0 (c), and $1.5 \mathrm{kA} \cdot \mathrm{m}^{-2}$ (d) in the $\mathrm{LIF}-\mathrm{NaF}-\mathrm{CaF}_{2}$ melt containing $2 \%$ $\mathrm{K}_{2} \mathrm{TaF}_{7}$.

of surface features are observed. One is a rather smooth deposit with crystalline facets. The other is the protuberances with relatively rough surface typical for dendritic growth. The number density of protuberances formed at $1.5 \mathrm{kA} \cdot \mathrm{m}^{-2}$ is higher in comparison with lower current densities.

Figure 6 shows SEM images of the electrodeposits obtained from sections after electrodeposition at $0.5(a, b)$, 1.0 (c) and $1.5 \mathrm{kA} \cdot \mathrm{m}^{-2}$ (d). A dense and compact deposit is formed by electrodeposition at 0.5 and $1.0 \mathrm{kA} \cdot \mathrm{m}^{-2}$. The smooth growth of crystallites seems responsible for forming the compact deposits. The deposit formed at $1.5 \mathrm{kA} \cdot \mathrm{m}^{-2}$ contains pores as shown in Fig. 6(d). As can be seen in Fig. 5(c), the boundaries of protuberances exhibit small gaps at the surface of the deposit. Those kinds of defects at the growing interface seem responsible for defects in the bulk of the coating prepared at high current density of $1.5 \mathrm{kA} \cdot \mathrm{m}^{-2}$.

Figures 7(a) and (b) shows a typical SEM image and the corresponding characteristic X-ray image of W-L $\alpha$, respectively, obtained after electrodeposition at $0.5 \mathrm{kA} \cdot \mathrm{m}^{-2}$ in the melt containing $2 \% \mathrm{~K}_{2} \mathrm{TaF}_{7}$. The interface has been roughly marked on Fig. 7(b) by dotted curve. The interface is invisible on SEM. Accordingly, a smooth, compact and defect-free interface has been formed. Similar results were found in all the electrodeposits obtained in the melt
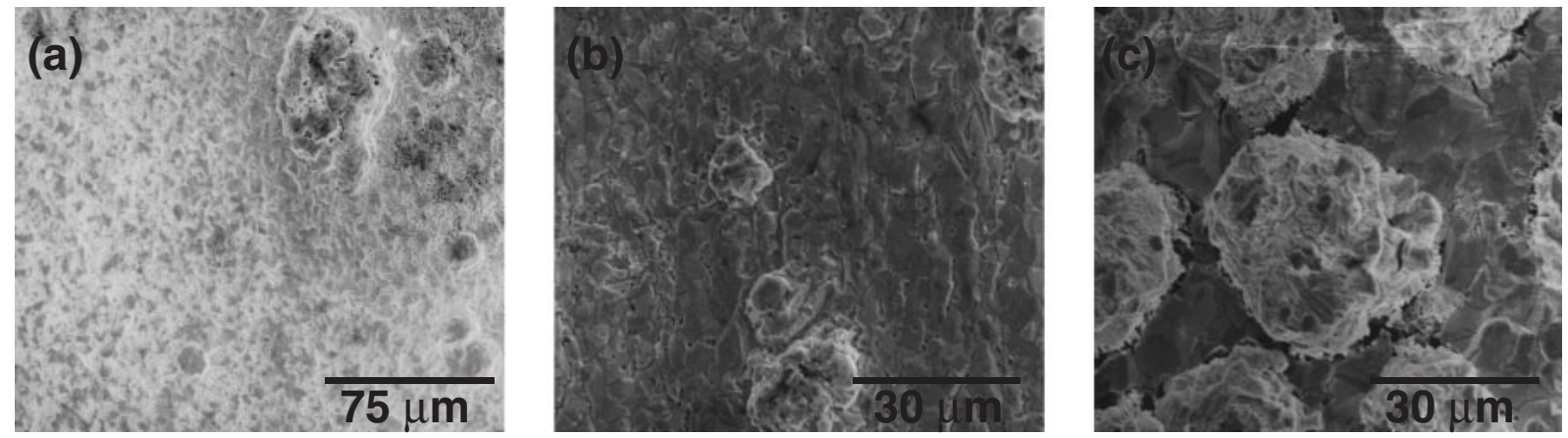

Fig. 5 SEM images of the electrodeposits' surfaces obtained at current densities of $0.65 \mathrm{kA} \cdot \mathrm{m}^{-2}$ for $2.4 \mathrm{ks}(\mathrm{a}), 1.0 \mathrm{kA} \cdot \mathrm{m}^{-2}$ for $0.9 \mathrm{ks}(\mathrm{b})$, and $1.5 \mathrm{kA} \cdot \mathrm{m}^{-2}$ for $0.9 \mathrm{ks}(\mathrm{c})$ in the $\mathrm{LiF}-\mathrm{NaF}-\mathrm{CaF}_{2}$ melt containing $2 \% \mathrm{~K}_{2} \mathrm{TaF}_{7}$. 

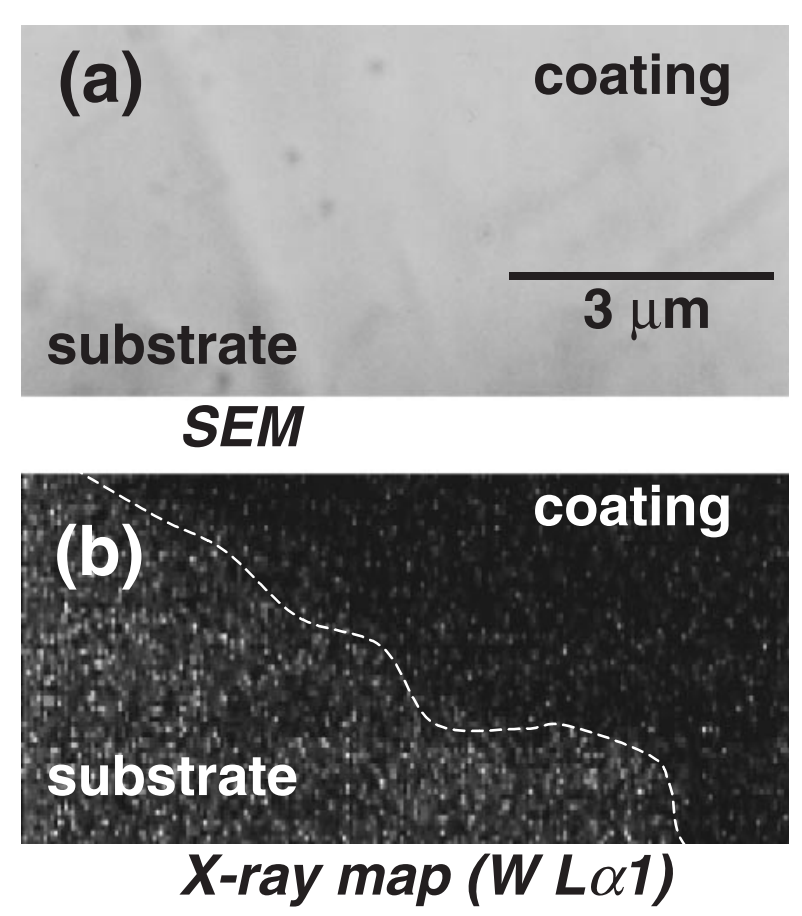

Fig. 7 SEM image and corresponding area X-ray map of tungsten obtained from a section including both the substrate and the coating. The electrodeposition was performed in the $\mathrm{LiF}-\mathrm{NaF}-\mathrm{CaF}_{2}$ melt containing $2 \% \mathrm{~K}_{2} \mathrm{TaF}_{7}$ at a current density of $0.5 \mathrm{kA} \cdot \mathrm{m}^{-2}$.

containing $2 \% \mathrm{~K}_{2} \mathrm{TaF}_{7}$.

It may be worth mentioning that a smooth and compact deposit completely covering the surface and making good interface with the substrate was not obtained on tungsten in the melt containing $1 \% \mathrm{~K}_{2} \mathrm{TaF}_{7}{ }^{17)}$ By contrast, sound deposits are obtained in the melt containing $2 \% \mathrm{~K}_{2} \mathrm{TaF}_{7}$. The conproportionation reaction may lead to preferential dissolution of thin dendrites if they form. Hence, it appears that a higher severity of conproportionation reaction has played a positive role in forming the smooth electrodeposits in the melt containing $2 \% \mathrm{~K}_{2} \mathrm{TaF}_{7}$, in comparison with $1 \%$ $\mathrm{K}_{2} \mathrm{TaF}_{7}$.

\section{Conclusions}

A compact coating of pure tantalum making a smooth interface is formed after galvanostatic polarization at 0.5 $1.0 \mathrm{kA} \cdot \mathrm{m}^{-2} \mathrm{LiF}-\mathrm{NaF}-\mathrm{CaF}_{2}$ melt containing $2 \% \mathrm{~K}_{2} \mathrm{TaF}_{7}$. At still higher current density, e.g., $1.5 \mathrm{kA} \cdot \mathrm{m}^{-2}$, the deposit contains some porosity due to partly dendritic growth. At very low current densities of $0.15-0.2 \mathrm{kA} \cdot \mathrm{m}^{-2}$, deposit is not obtained on most of the surface due to difficulty in nucleation as a result of conproportionation reaction. The conproportionation reaction does not result in contamination of the deposit because of soluble nature of the conproportionation product.

\section{Acknowledgements}

One of the authors $(\mathrm{mm})$ is grateful to Japan Society of Promotion of Sciences (JSPS) for post-doc fellowship. The authors are thankful to Mr. H. Iijima and Mr. T. Izumi of Showa Cabot Supermetals Co. for providing us with Potassium Fluorotantalate powder. The authors are also thankful to Dr. E. G. Polyakov for useful advice.

\section{REFERENCES}

1) K. Hashimoto, P. Y. Park, J. H. Kim, H. MiTsui, E. Akiyama, H. Habazaki, A. Kawashima, Z. Grzesik, S. Morwee: Mater. Sci. Eng. A-Struct. 198 (1995) 1-10.

2) M. Mehmood, B. P. Zhang, E. Akiyama, H. Habazaki, A. Kawashima, K. Asami and K. Hashimoto: Corros. Sci. 40 (1998) 1-17.

3) M. Mehmood, E. Akiyama, H. Habazaki, A. Kawashima, K. Asami and K. Hashimoto: Mater. Sci. Forum 289-292 (1998) 629-639.

4) M. Mehmood, E. Akiyama, H. Habazaki, A. Kawashima, K. Asami and K. Hashimoto: Corros. Sci. 41 (1999) 477-499.

5) M. Mehmood, E. Akiyama, H. Habazaki, A. Kawashima, K. Asami and K. Hashimoto: Corros. Sci. 41 (1999) 1871-1890.

6) M. Mehmood, E. Akiyama, H. Habazaki, A. Kawashima, K. Asami and K. Hashimoto: Corros. Sci. 42 (2000) 361-382.

7) K. Asami, B. P. Zhang, M. Mehmood, H. Habazaki and K. Hashimoto: Scripta Mater. 44 (2001) 1655-1658.

8) M. Mohamedi, Y. Sato and T. Yamamura: Electrochim. Acta 44 (1999) 1559-1565.

9) M. Mohamedi, N. Kawaguchi, Y. Sato and T. Yamamura: J. Alloy Comp. 287 (1999) 91-97.

10) D. Inman and S. H. White: J. Appl. Electrochem. 8 (1978) 375-390.

11) T. Yamamura, S. Mizuno, T. Nito, M. Endo, Y. Sato and T. Ejima: J. Japan Inst. Metals 56 (1992) 889-896.

12) T. Yamamura, Y. Sato, H. M. Zhu, M. Endo and Y. Sato: ISIJ Int. 33 (1993) 176-181.

13) H. M. Zhu, K. Iwabuchi, Y. Sato and T. Yamamura: Jpn. J. Appl. Phys. 133 (1994) 3220-3225.

14) Y. Sato, M. Fukasawa, K. Abe and T. Yamamura: Electrochemistry 67 (1999) 563-567.

15) Y. Sato, Y. Matsuzaki, M. Uda, A. Nagatani and T. Yamamura: Electrochemistry 67 (1999) 568-572.

16) J. Ahmad, K. Asami, A. Takeuchi and A. Inoue: Mater. Trans. 44 (2003) 705-708.

17) M. Mehmood, N. Kawaguchi, H. Maekawa, Y. Sato, T. Yamamura, M. Kawai and K. Kikuchi: Mater. Trans. 44 (2003) 259-267.

18) A. J. Bard and L. P. Faulkner: Electrochemical Methods (2nd Edition), (John Wiley \& Sons, Inc., New York, 2001). 